\title{
Designação e acontecimento
}

\author{
Designation and event
}

\author{
Eduardo Guimarães ${ }^{1}$ \\ DL-IEL/Labeurb - Unicamp \\ UNEMAT/CNPq
}

\begin{abstract}
O objetivo deste texto é refletir sobre a relação de designação na prática linguística. Nesta medida daremos atenção específica à relação do processo de designação com o acontecimento de enunciação.

Antes de tratar da questão que apresentei na ocasião do VIII Enalihc, em 2018, gostaria de me valer desta ocasião para agradecer a homenagem que me fizeram com este evento, de modo particular na sessão de abertura, tomando-me de surpresa. Agradeço assim à Unemat, agradeço particularmente ao Programa de Pós-graduação em Linguística e ao CEPEL, e aos organizadores do evento; agradeço a todos que estiveram presentes ou enviaram depoimentos relativos a nossas relações de trabalho por todos esses anos, na Unicamp e na Unemat, e em tantas outras universidades brasileiras onde pesquisadores que se interessam pela significação da linguagem têm me dado a oportunidade de uma convivência rica, humana e proveitosa.

Começo retomando minha definição de designação. A designação de uma palavra "é sua significação enquanto algo próprio das relações de linguagem e também, e por isso mesmo, enquanto uma relação simbólica exposta ao real, enquanto uma relação tomada na história. Deste modo a designação identifica objetos, tal como diria Rancière (1992)" Guimarães $(2002$, 2018).

A designação de uma palavra, tal como vimos considerando ${ }^{2}$, é uma relação da linguagem com o existente. É por esta relação que o que existe toma sentido. De nosso ponto de vista, é em virtude desta relação de significação que é possível falar do existente, o que torna possível, inclusive, referir-se a ele. A designação, como a significação em geral, constitui-se pela enunciação. Nesta medida a designação se dá na prática de linguagem e produz, incessantemente, uma partilha do real, no sentido que esta expressão tem em Rancière (1995).

Para a presente reflexão vou me dedicar a duas sondagens a propósito de duas palavras das quais vou analisar o funcionamento enunciativo, liberdade e caraíba. A primeira é uma palavra indo-europeia, a segunda uma palavra do tupi. São percursos históricos diferentes, permitindo observar uma palavra que se constitui numa história de enunciações e outra em outra história, formam-se, portanto, em espaços de enunciação diferentes.
\end{abstract}

\section{$1 . O$ sentido de Liberdade em um Manifesto no Século XIX}

Comecemos pela observação do sentido da palavra liberdade num texto do século XIX. Trata-se de uma palavra-conceito que vou tomar em enunciados do texto Manifesto da Confederação Abolicionista do Rio de Janeiro ${ }^{3}$. A designação desta palavra se

\footnotetext{
${ }^{1}$ Doutor em Linguística pela USP. Professor Titular da Universidade Estadual de Campinas e Professor Visitante da Universidade do Estado de Mato Grosso. E-mail: eduardo.gui@uol.com.br

${ }^{2}$ Guimarães (2002, 2007, 2018)

3 Trata-se do Manifesto escrito por José do Patrocínio.
} 
constitui como um valor em espaços de enunciação das línguas indo-europeias no percurso que vem da história Greco-romana.

No Manifesto encontramos o seguinte enunciado ${ }^{4}$ :

(1) a liberdade natural do homem é um direito imprescritível.

No texto em questão, o enunciado (1) é um argumento decisivo para a defesa da abolição da escravidão no Brasil ${ }^{5}$. Este enunciado apresenta uma relação predicativa específica. De um lado a formação nominal sujeito a liberdade natural do homem e de outro a predicação é um direito imprescriptível. Esta relação predicativa traz uma relação de reescrituração por definição que atribui direito a a liberdade natural do homem. Ao mesmo tempo, a formação nominal sujeito nos apresenta uma nominalização (a liberdade natural do homem) que condensa numa formação nominal a relação predicativa $a$ liberdade do homem é natural ${ }^{6}$. Nesta medida, podemos considerar que direito determina enunciativamente (atribui sentido a) liberdade, assim como natural (direito $\dashv$ liberdade $\vdash$ natural).

Observemos agora um outro enunciado do Manifesto:

(2) O estuário da escravidão entre nós teve duas vertentes: a espoliação da liberdade dos íncolas por um lado; a espoliação da liberdade dos africanos, por outro.

Escravidão é reescriturado por espoliação da liberdade em espoliação da liberdade dos íncolas e espoliação da liberdade dos africanos. Ou seja, espoliação determina enunciativamente escravidão na medida em que escravidão é sinônimo de espolição da liberdade (escravidão - espoliação da liberdade). Isto nos leva a considerar que liberdade significa, no texto, em antonímia a escravidão.

Diante destes elementos de análise, podemos considerar que a designação de liberdade neste texto, tal como aparece neste argumento, é:

DSD -1

\begin{tabular}{|l|}
\hline direito -liberdade F natural \\
\hline escravidão - espoliação da liberdade \\
\hline
\end{tabular}

Só para mostrar como esta relação de significação é própria deste texto, embora possa se apresentar também em outros, observemos, por exemplo, o que encontramos sobre a palavra liberdade no Dictionnaire des Sciences Sociales (Mesure e Savidan, 2006):

"A liberdade, pelo menos nas discussões que têm sido feitas em filosofia política, tende a designar uma propriedade que possui ou não as pessoas que vivem em sociedade. (p. 705)

Sem me deter em uma análise específica, o que vemos é que o sentido de liberdade significa algo que as pessoas podem ou não ter em sociedade. Não se trata, portanto, necessariamente, para esta definição, de uma propriedade natural. Outro aspecto a considerar é que há, nesta definição, uma concepção sobre a relação conceito-palavra na qual os conceitos independem das palavras que, nesta perspectiva, os expressam.

Um outro registro comparativo pode ser feito, por exemplo, observando o verbete de um dicionário da língua portuguesa (Dicionário Aurélio, Hollanda Ferreira, 2004);

\footnotetext{
${ }^{4} \mathrm{O}$ sentido de um enunciado é seu modo de integração a um texto, num acontecimento de enunciação (Guimarães, 2002, 2011, 2018).

${ }^{5}$ Tratei deste aspecto, do ponto de vista argumentativo em Guimarães (2018a).

${ }^{6}$ Podemos, em certa medida, parafrasear a liberdade natural do homem por a liberdade do homem é natural ou, o que dá mais ou menos no mesmo, por o homem tem uma liberdade natural.
} 
Liberdade. Sf. 1. Faculdade de cada um de decidir ou agir segundo sua própria determinação. 2. Estado ou condição de homem livre. 3. Confiança, intimidade (às vezes abusiva) Liberdade condicional jur. Liberdade, com algumas condições restritivas, que se dá a certos condenados, antes do fim da pena (p. 515 Mini Aurélio, 6 a . Edição. Positivo)

Também aqui apresenta-se um "conceito" de liberdade, que independe das palavras e que não vincula a liberdade à natureza.

Voltando a nossa análise, o que se observa é que o que chamamos designação se constitui no acontecimento de enunciação. O sentido de liberdade, no caso do enunciado (1), não precede, mas é constituído pela prática linguística. A designação dá (atribui) sentido às coisas existentes. A enunciação toma o existente, enquanto significado (por ser significado). Não se trata, no caso da designação de liberdade no DSD-1, de uma relação referencial, mas de uma relação de significação sem a qual não há linguagem e não é possível falar das coisas. Fala-se da liberdade em virtude da designação da palavra liberdade no texto em que se enuncia o argumento apresentado por (1).

O funcionamento da designação se constitui na relação da enunciação com aquilo de que ela fala, que se apresenta na linguagem enquanto a linguagem o significa.

É importante aqui notar a relação que se apresenta nesta passagem entre argumentação e designação. De um lado (1) é, no texto, argumento contra a escravidão, por outro lado a constituição da designação de liberdade dá ao argumento uma força decisiva. $\mathrm{O}$ argumento constitui um sentido de liberdade tal que a escravidão é inaceitável, por ser significada como algo antinatural, como supressão de um direito natural, como, portanto, um desrespeito à própria natureza da humanidade, das pessoas.

Passemos a uma outra análise, a da designação da palavra caraíba, que se apresenta em português em virtude da relação do tupi com o português no século XVI.

\section{Caraíba ou Caraíba}

Encontram-se, no século XVI, muitos textos em momentos em que se apresenta o que seria o sentido de caraíba em português, e também na língua indígena (tupi). Antes de irmos ao século XVI, observemos que esta palavra, como todos sabemos, é encontrada, no século XIX, em português, numa passagem de Ubirajara de José de Alencar, no capítulo inicial da obra, "O Caçador":

- [Jaguarê] Eu sou Jaguarê, filho de Camacã, chefe da valente nação dos araguaias, que vem de longe em busca da terra de seus pais. [Minha fama corre as tabas e tu já deves conhecer o maior caçador das florestas. Mas Jaguarê despreza a fama do caçador; ele quer um nome de guerra, que diga das nações a força de seu braço e faça tremer aos mais bravos. Se tua nação te aclamou forte entre os fortes, preparate para morrer; se não, passa teu caminho, guerreiro vil, para que o sangue do fraco não manche o tacape virgem de Jaguarê.

-[Pojucã] O caraíba guiou teu passo ao encontro de Pojucã, o matador de gente, guerreiro chefe da terrível nação tocantim, que enche de terror as outras nações. Há três luas, desde que fugiram espavoridos os bárbaros tapuias, que Pojucã não combate; e seu tacape tem fome do inimigo. Tu não és digno dos golpes de um guerreiro chefe; mas Pojucã se compadece de tua mocidade e consente em combater contigo. Terás a glória de ser morto pelo mais valente guerreiro tocantim. Os cantores de meus feitos lembrarão teu nome; e todos os mancebos de tua nação invejarão tua sorte. 
Nesta passagem a palavra caraíba ${ }^{7}$ aparece designando um indígena com um papel específico na sociedade deles. Estes indígenas, por relatos sobre a palavra caraíba, são também chamados pajés.

Um outro caso interessante de presença da palavra em português, em momentos posteriores ao século XVI, é a etimologia feita por couto de Magalhães em O Selvagem:

"Na costa Caraíba, no Paraguay caraí. A raiz car ou ra involve a idéa de dilaceração, e entra na composção de muitos nomes de vegetaes providos de espinhos retorcidos como garas, nos das aves e animaes que tem garras exemplos: Taquára, caragua á, carandá, marajá,, (vegetaes de espinhos retorcidos); caracará Gavião, carará corvo d'água, iauára cão, iaráeté onça, auará lobo, caráin arranhar, esfollar. A segunda raiz iba iua significa ruim; de modo que o branco foi designado pelo selvagem da America, com duas raízes que exprimem a idéa que elles formaram a principio de nossa raça, isto é: a raça voraz e má; a historia das primeiras conquistas mostra que para elles essa designação era tão real quanto vergonhosa para nós. Por mais injurioso que seja o nome, elle ha de passar a mais remota posteridade, castigo indelével do sangue que derramamos, dos latrocínios e rapinas que fizemos entre elles!" (Couto de Magalhães, 1876, p. 87)

Vamos agora a alguns dos relatos acima referidos. Anchieta, por exemplo, quando está apresentando os pajés, ele os refere por feiticeiros, uma palavra de língua neolatina, que re-significa, nos termos da língua portuguesa e de enunciações nesta língua, pajés por feiticeiros, e, nesta medida, significa os pajés na tradição católica européia. Re-identifica, portanto, os pajés. E ao falar destes pajés (feiticeiros, na palavra de Anchieta, e também de outros portugueses) encontramos:

(6)“'Todas estas invenções ${ }^{8}$ por um vocábulo geral chamam caraíba, que quer dizer como cousa santa, ou sobrenatural; e por esta causa puseram este nome aos portugueses, logo quando vieram, tendo-os por cousa grande, como do outro mundo, por virem de tão longe por cima das águas.” (Anchieta, Cartas, p.332)

Temos, então, um registro da palavra caraíba, em português, que enuncia uma definição para ela (coisa santa ou sobrenatural) que o texto de Anchieta atribui a indígenas considerados como santos (para usar uma palavra cristã católica), ligados ao sobrenatural. E aparece também o relato de que os indígenas deram este nome aos portugueses por considerá-los como alguém de "outro mundo", "cousa grande". Não nos esqueçamos que, como dissemos, o nome em língua portuguesa, na enunciação de Anchieta, para estes caraíbas (pajés), é feiticeiros. Assim, nas enunciações de Anchieta, caraíba significa feiticeiros enquanto designa os indígenas, pajés (feiticeiros $\nmid$ caraíba - pajé), e significa "cousa grande" enquanto designa os portugueses e aparece assim, como sinônimo de português (cousa grande $\dashv$ caraíba - português).

Segundo Anchieta, enquanto seu relato é o relato dos usos da palavra caraíba, em tupi, mesmo que enunciada em português em (6), há em tupi, de um lado

DSD -2

Feiticeiro

\footnotetext{
${ }^{7}$ É sua única ocorrência no romance.

${ }^{8}$ Feiticeiros e suas práticas.
} 


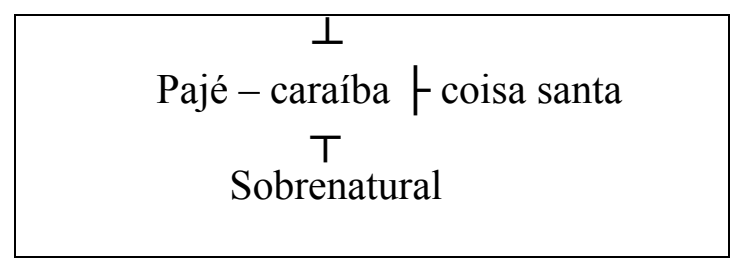

E de outro

DSD -3

$$
\begin{gathered}
\text { Português - caraíba } \vdash \text { coisa grande } \\
\top \quad \text { do outro mundo }
\end{gathered}
$$

Não podemos deixar de observar que, na medida mesmo em que Anchieta nos relata, está enunciando a palavra caraíba em português. E no relato vemos se produzir um movimento de sentido que se faz pela predominância política do português como língua oficial, no conflito com o tupi. De um lado a descrição de Anchieta atribui um sentido a caraíba que é um sentido cristão (feiticeiro), e não indígena. Por outro é como se esta descrição para o tupi fosse a mesma para a palavra em português. Na narrativa de Anchieta o português aparece como a língua com a qual se fala dos sentidos das palavras em tupi, e para tanto enuncia a palavra em português.

Há outros relatos a propósito desta palavra por outros autores, mas o nosso objetivo não é analisar, na extensão de seu funcionamento, a palavra caraíba (em tupi ou em português). Detenhamo-nos nisto que acabamos de colocar, para a reflexão sobre a constituição da designação no acontecimento de enunciação.

É interessante observar também que a palavra caraíba em Ubirajara de José de Alencar aparece marcada por esse cotejo político de línguas, funcionando em português com a designação numa configuração semelhante ao sentido que se apresenta no DSD-2, mas não há nada no texto do romance que atribua a esta palavra o sentido negativo da determinação por feiticeiro. No domínio da narrativa ficcional há um lugar de alocutor que enuncia, como do lugar do índio, como se fosse em tupi, e assim não funciona a determinação negativa. Teríamos neste caso a seguinte designação:

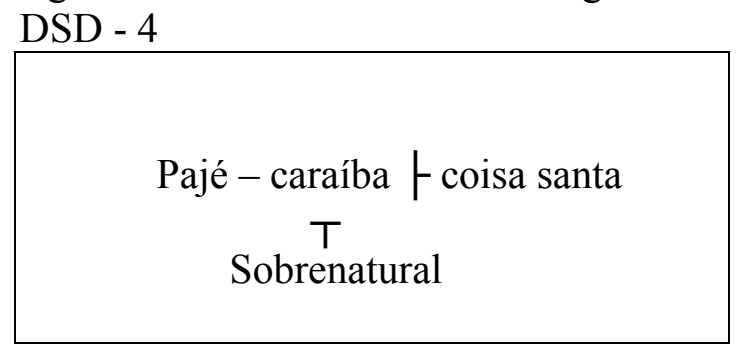

Voltando à enunciação de Anchieta, vemos que a configuração das designações para caraíba significa aí um litígio de línguas. Caraíba em português tem dois sentidos, divide o real por uma designação positiva e outro negativa, como se isso fosse a palavra em tupi. Por outro lado, são significados não só em português, mas do lugar do colonizador e metaforizados como feiticeiros. Quanto ao Tupi, só podemos pensar que esta palavra deveria ter algo que pode ser aproximado do que apresentamos no DSD -4 e DSD - 3. Esta aproximação pode ser feita a partir da consideração dos lugares de enunciação (no caso do lugar de alocutor) na cena enunciativa. 
Por outro lado, e isso é decisivo aqui, a consideração da palavra caraíba, no relato de Anchieta e em outros, nos coloca diante de um litígio de línguas; diante de uma disputa de sentido entre línguas: esta palavra é de qual língua e o que ela significa em cada língua? Este litígio nos coloca diante de uma disputa pelo sentido de uma palavra que, ao entrar na língua portuguesa, tem seu sentido metaforizado pelo memorável das enunciações em língua portuguesa (feiticeiros), e pelo desconhecimento do memorável das enunciações em língua indígena (pajés).

A palavra caraíba significa nesta história esta tensão permanente e que não se resolve, mesmo que esta tensão tenha sido esquecida pelo desuso. Caraíba não é hoje senão um arcaísmo, uma palavra que não faz mais parte, senão para descrever o passado. Mas que o significa sempre.

\section{Consideração metodológica}

Antes das considerações sobre as duas sondagens feitas para a reflexão sobre o processo de designação, podemos pensar sobre a questão da produção de conhecimento sobre as línguas numa condição não pouco comum. Isto aparece aqui, pela análise dos relados de Anchieta sobre a palavra caraiba, que podemos relacionar com a palavra em Alencar e com a etimologia de Couto de Magalhães. O conhecimento (descrições, análises) sobre a linguagem, num espaço de enunciação, tal como neste caso, na língua proeminente deste espaço, politicamente legítima, se produz do lugar de alocutor que se alinha com o falante da língua proeminente (no caso aqui considerado os falantes de língua portuguesa). A produção de conhecimento aparece assim como um caminho oblíquo pelo qual pode tornar-se impossível chegar a uma análise na qual se tenha de fato tocado a realidade que se descreve. Faço esta consideração, mesmo que ela possa ser um tanto imprecisa. O que me interessa registrar é como o espaço de enunciação é parte das condições históricas da produção do conhecimento, pelo menos nas ciências da linguagem.

\section{Considerações sobre Liberdade e Caraíba}

As duas sondagens, feitas na seção 2, trazem a análise do funcionamento da designação que nos leva a poder dizer, claramente, a constituição da significação, e da designação em particular, se produz numa relação própria da prática linguística:

1)São relações de enunciação específicas que constituem o sentido destes nomesconceito num texto particular, que se distinguem da constituição do sentido da mesma palavra em outros textos. Não se trata de dizer que há um sentido que se especifica, pois o que há, continuamente, é um confronto de sentidos (uma relação política ${ }^{9}$ ). O que há são sentidos diversos cuja história é sempre um litígio. Isto pode se significar como constituindo uma polissemia do termo ou mesmo um antonímia, numa contradição constitutiva.

2)São relações de línguas num espaço de enunciação específico, o das línguas tupi (ou línguas indígenas em geral) e português a partir do século XVI. No caso específico de caraíba são as relações de língua que tornam possível, na ausência de dados, encontrar

\footnotetext{
${ }^{9}$ A consideração do político tomo aqui a partir da noção de confronto (Orlandi, 1990), e levando em conta a reflexão de Rancière (1995). Nesta medida posso formular a questão como uma relação enunciativa, no espaço de enunciação e na cena enunciativa (Guimarães, 2002).
} 
um movimento de relações de enunciações relatadas que são parte decisiva do que a palavra designa num momento específico.

3)São relações de línguas que podemos seguir pela observação da história que a palavra, no caso de liberdade, tem num percurso do indo-europeu ao português, questão sobre a qual não me detive aqui.

As duas sondagens nos levam a pensar nos sentidos como constituídos na relação da enunciação com aquilo sobre que fala e não como um conceito pré-existente que a palavra expressa no texto específico, pois o que as sondagens nos permitiram observar é que não se trata do mesmo conceito, ou seja, o conceito é o que é o próprio sentido do termo produzido enunciativamente. Por outro lado, tanto num caso como noutro, é decisivo que se considere o existente, pessoas que fazem coisas específicas, num modo específico de a sociedade distribuir politicamente identificações: ser santo ou ser feiticeiro; ser proprietário ou ser escravo. Ou seja, o que existe entra na nossa relação enquanto significado. Não se trata da precedência do conceito que a linguagem expressaria, nem da precedência do real, sobre o qual a linguagem falaria, nem tampouco da precedência da linguagem sobre as coisas. Trata-se do acesso que temos ao existente porque há linguagem.

\section{REFERÊNCIAS}

Hollanda Ferreira. A. (2004) Mini Aurélio. Curitiba, Positivo. 6 ${ }^{\mathrm{a}}$. Edição revista e atualizada.

Anchieta, J. (1933) Cartas Jesuíticas III. Cartas. Informações, fragmentos históricos e sermões (1554-1594). Civilização Brasileira. Rio de Janeiro.

Couto de Magalhães, (1876) O Selvagem I - Curso de Lingua Geral pelo Método de Ollendorf . Rio de Janeiro, Typographia da Reforma.

Guimarães, E. (2002) Semântica do Acontecimento. Campinas, Pontes.

Guimarães, E. (2007) “Domínio semântico de Determinação" Palavra: Forma e Sentido na Linguagem. Campinas, Ponte/RG.

Guimarães, E. (2011) Análise de Texto. São Paulo Hucitec (2012).

Guimarães, E. (2018). Semântica: Enunciação e Sentido. Campinas, Pontes.

Guimarães, E. (2018a) "O Argumento da Liberdade: Sondagens em um Manifesto Abolicionista no Século XIX". IV Jornadas da Associação Latino-Americana de Retórica e V Congresso Brasileiro de Retórica, Belo Horizonte. UFMG.

Mesure, S. e Savidan, P. (2006) Le Dictionnaire des Sciences Humaines. Paris, PUF.

Orlandi, E. (1990) Terra à Vista. São Paulo, Cortez / Editora da Unicamp.

Rancière, J. (1992) Os Nomes da História. Campinas, Pontes, 1994.

Rancière, J. (1995) O Desentendimento. Rio de Janeiro, 34, 1996.

Recebido em: novembro de 2019.

Como citar este trabalho:

Aprovado em: dezembro de 2019.

GUIMARÃES, E. Designação e Acontecimento Traços de Linguagem. V.3, n.2, p. 97-103, 2019. 